\title{
La drogadicción como huída. Condicionamientos sociales de las toxicomanías
}

\section{José Ortega}
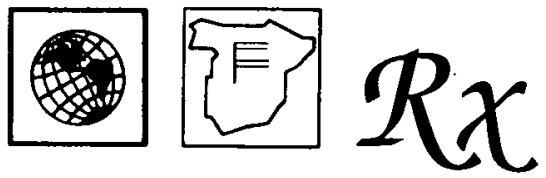

En el artículo se propone un planteamiento ecológico o ecosistémico para abordar el fenómeno de las drogas y sus posibles soluciones; planteamiento que permite recoger las aportaciones de los posicionamientos relativos al medio ambiente físico $y$ aquellas concepciones más atentas al medio bumano.

\section{«PROLOGOS»}

Hace ya bastantes años que el mundo occidental, sobre todo Europa, se preocupa, aunque no lo suficiente, por el deterioro paulativo y progresivo del medio ambiente, de la naturaleza física, del ecosistema geográfico y natural en el que vive el hombre y, sin embargo, por no sé qué extraña circunstancia, no parece preocuparnos el no menos palpable deterioro del medio humano, del hecho humano (Proyecto Homo, 1992), de todo aquello que hace posible la relación, la convivencia, la cultura y el desarrollo positivo de lo humano. Muchos son los hechos, acontecimientos, circunstancias y factores que contribuyen a esta degradación de la realidad humana, de sus contextos y de sus potencialidades de mejorar en este último tercio del siglo XX, pero está claro que uno de esos factores es el progresivo y abusivo consumo de drogas y sus consecuencias.

El concepto de huida en relación con la adicción a las drogas puede considerarse como un concepto abstracto y literario, incluso metafísico y transcendente o psicológico y social.

En este sentido, podríamos relacionar con la adicción no sólo el concepto de huida sino también el de búsqueda.

Al hablar aquí de los condicionamientos sociales de las toxicomanías, no parece que tenga espacio para la metafísica o la literatura. Posiblemente, dada la tragedia humana y social que conlleva la realidad de las drogas, la utilización del discurso metafísico y estético podría ser interpretada por alguno precisamente como una huida de la realidad social y de nuestras responsabilidades. No obstante, quiero dejar constancia aquí de la virtualidad sugerente y comprensiva de los conceptos de huida y búsqueda desde una perspectiva platónica y anselmiana, como abstracciones ontológicas que «en última instancia», hacen inteligible el fenómeno personal y colecti- 


\section{8}

vo de la droga, de la misma forma que el eros cósmico platónico hacía comprensible por derivación cualquier manifestación erótica o sexual por desviada y negativa que fuera. Intento aquí algo más prosáico y convencional, hablar de los condicionamientos sociales y psicológicos del consumo abusivo de las drogas, aspecto, por otra parte, muy manido y controvertido, en relación con el cual, más que describir las diversas clasificaciones, voy a apuntar algunas consideraciones críticas.

Estas consideraciones, después de indicar las clasificaciones de causas y factores más comunes, se refieren, entre otras cosas, al analiticismo y psicologismo excesivo, todavía vigente, que se separa de una consideración más radical e integrada de los condicionamientos del abuso de las drogas y de la conciencia de las responsabilidades compartidas de toda la sociedad.

Un planteamiento ecológico o eco-sistémico del problema que recoja el paralelismo indicado al principio entre las concepciones y posiciones relativas al medio ambiente físico con las del medio humano puede facilitar una comprensión más acertada del fenómeno de las drogas y sus posibles soluciones.

\section{«LOGOS»}

Muchas son las causas, factores variables y motivaciones que se indican como determinantes, inductoras o que se relacionan con la toxicomania o el uso abusivo de drogas. Depende de los autores y los conocimientos científicos de los que parten. Biólogos y médicos suelen encontrar etiologias fisiológicas y patológicas, psicólogos y psiquiatras rasgos de personalidad, motivaciones psicológicas, neuroticismos, etc. Los sociólogos ven circunstancias y factores de cambio y crisis social implicados en el consumo de drogas; los antropólogos consideran aspectos culturales; los teólogos cri'sis religiosas y morales de los indivíduos y las sociedades. Los resultados de los análisis y diagnósticos de causas o factores, además del enfoque científico y de la teoría científica o ideológica en la que cada uno se situa, dependen también de los mismos instrumentos de análisis.

La mayoría de las investigaciones que se han hecho hasta el momento se han realizado a un nivel individual y preferentemente a sujetos «enfermos» e institucionalizados en hospitales, centros de tratamiento, reformatorios, cárceles, etc., lo que ha podido sesgar los resultados. Menos investigaciones se hacen a un nivel microsociológico en el que se analicen las variables relacionadas de los drogadictos con grupos sociales e instituciones y escasamente hay investigaciones a un nivel macrosociológico en el que se analicen factores relativos al contexto económico y social de los individuos que se drogan. Por supuesto, a nadie se le ha ocurrido analizar la calidad del medio bumano en el que ese individuo drogadicto vive.

Las conclusiones de todas estas investigaciones y análisis, en general, han sido poco claras y nada concluyentes, constatándose saturaciones e interconexiones de las diversas variables. Podríamos echar la culpa de estos resultados al número, todavía pequeño, de investigaciones, o a la falta de precisión o finura de los análisis, pero yo creo que se debe más al mismo enfoque y planteamiento de los análisis del problema y a su discordancia con la realidad. Además de los sesgos de oficio, ideológicos y metodológicos a los que nos hemos referido anteriormente.

En efecto, en general, esas investigaciones se han dirigido al análisis individual de los drogadictos en los que han encontrado fundamentalmente características psicológicas o psiquiátricas y, como no podía ser menos, han encontrado lo que buscaban. Podrían haber estudiado el grupo o los grupos sociales, la comunidad, el medio ambiental y el medio humano en el que viven esos indivíduos. Incluso cuando los análisis se han hecho con el fín de implementar planes, programas o proyectos preventivos o secundarios comunitarios los estudios han sido individuales o sumativos. Pero, lógicamente los estudios de análisis o diagnóstico previos deben participar de la lógica comunitaria. Entre el diagnóstico y la intervención debe existir coherencia. 
No se puede hacer un análisis individual o de individuos y luego implementar un programa comunitario en base a esos datos, aunque se hayan acumulado o yuxtapuesto. Lo colectivo es diferente de la suma de los individuos que lo componen.

Los planteamientos y diseños de las causas, factores o condiciones de la toxicomanía deben ser integradores, interrelacionales, comunitarios, que eviten perder la visión unitaria e integrada del conjunto, su progresión y conexión. Planteamientos estructurales, sistémicos, ecológicos (hace tiempo que se habla de «ecología del delito» Jiménez Burillo y Aragonés, 1986) antropológicos y cualitativos, se conformarían mejor a la realidad del fenómeno de los procesos complejos de la drogadicción. Lo que, por supuesto, no debe impedir estudios individuales psicológicos o psicopatológicos como complementarios. Los planteamientos estrictamente analíticos, al «desintegrar» y aislar los factores etiológicos de la drogadicción, nos despistan de la genética de las causas y dispersan y difuminan las responsabilidades a compartir por parte del colectivo social y a su vez nos alejan de la realidad ecológica, sistémica, conexionada y dinámica de los procesos sociales.

Debe quedar claro que hablando de las causas de la toxicomanía ninguna de las que se citan pueden predecirla de manera inevitable (Repetto y cols., 1985), esto es, no podemos tener una posición determinista en el sentido de que un factor aislado o varios factores concatenados o sucesivos puedan conducir necesariamente a consumir abusivamente drogas, ya que a unos individuos pueden llevar a la drogadicción y a otros a buscar satisfacciones no relacionadas con las drogas (La dependencia de las drogas, 1981). En efecto, no se ha logrado aislar una causa como determinante exclusivo de la toxicomania. En este sentido es frecuente, más que hablar de causas, hablar de factores, condicionamientos o motivaciones. Nos movemos, en general, en el terreno de las hipótesis interpretativas, sin contrastación empírica, en base a posiciones fundamentalmente ideológicas, más o menos verosímiles y razonables.

Incluso para conductistas, neoconductistas y algunos cognitivistas, las investigaciones sobre las causas son innecesarias para solucionar el problema de la toxicomania. En este sentido, p.ej., el Modelo H.B.M. de Becker y Marshal (1974) y de Strickland (1978)., parte de la tesis de que «los hechos sociales tienen menos importancia para el comportamiento que la manera en que se perciben» (González y Pérez de Villar, 1993), por lo que es necesario modificar las percepciones, pero no estudiar los hechos ni sus causas. Otros modelos de tratamiento preventivo de las toxicomanias como el P.R.E.C.E.D.D. (Predisposing, Reinforcing, Enabling Causes for Educational Diagnosis and Evaluation, Green, 1980), por el contrario, dan gran importancia al estudio de los factores que predisponen, refuerzan o facilitan el abuso de las drogas (González y Pérez de Villar, 1993,), factores que deben ser diagnosticados antes de la intervención.

Personalmente entiendo que el estudio de los factores que tienen parte en el origen de la toxicomanía orienta las soluciones del problema y que para prevenir, controlar y disminuir esta lacra deberemos localizar los factores originantes y su mayor o menor influencia (Repetto y cols., 1985).

Por otra parte, el estudio y análisis de los factores influyentes en el abuso de las drogas nos lleva a primar la prevención frente a la terapia ex post facto. El escaso éxito de los tratamientos conductistas o de caja negra, nos conduce a primar los programas y proyectos comunitarios y educativos.

No obstante, debemos ser conscientes de las limitaciones de los análisis de los factores que originan el consumo de drogas, además de lo ya apuntado, ya que pueden variar en función de las personas, del tipo de droga o del mismo contexto social. «Diferentes personas pueden utilizar distintas drogas por el mismo motivo, o la misma droga por diferentes motivos; una misma persona puede alternar diversos motivos para consumir una droga determinada» (Repetto y cols., 1985). Los factores que favorecen el comienzo del consumo de una droga pueden ser distintos de los que promueven su persistencia. No hay teorias etiológicas universales, ni salidas para todo lugar o tiempo (Vega Fuente, 1985). 
Dicho lo cual, y seguro de que los estudios de factores causales conllevarán alguna otra limitación que en este momento olvido, sigo pensando en la necesidad de presentar estudios, investigaciones y teorias que vayan poco a poco acotando y aclarando la etiología de la drogadicción. Es por lo que quiero formular ahora un modelo integrado (en espiral) de los factores que intervienen o pueden intervenir en ese proceso dinámico y conexionado que conduce al uso abusivo de las drogas. Este viene a ser la proyección a la drogadicción del modelo que comencé a desarrollar en 1977 en relación con el fenómeno de la delincuencia juvenil (Ortega Esteban, 1978) y que recoge aspectos del «modelo globalizador de las toxicomanías» de la Organización Mundial de la Salud, (O.M.S., Nomenclature and Classification of drug and alcohol related problems: a WHO Memorandum, Bull WHO, 59, (225-242) citado en Valbuena Briones, 1993) y de otros modelos también complejos y globales, como el modelo de «causación circular acumulativa» (Vega Fuente,1985).

A mi entender, podemos decir plausiblemente, que se dan tres niveles interrelacionales e interdependientes, acumulativos y complementarios y, en general, sucesivos, que, con todas las limitaciones que hemos indicado anteriormente, pueden conducir al uso y abuso de las drogas:

1. Un nivel de factores, que podemos llamar profundos o remotos, —o también lejanos, radicales, y, en cierto sentido, históricos e, incluso, estructurales- son aquellos de orden socio-económico, socio-estructural, socio-políticos, antropológicos, culturales e ideológicos, ambientales y ecológicos.

Podríamos concretarlos en una inadecuada distribución de la renta nacional, de la cultura y la educación, estructuras basadas en el lucro de los menos, una organización autoritaria y opresiva de la sociedad y de la vida cotidiana, medio ambiente físico y medio humano deteriorados, presión de las costumbres y modelos sociales establecidos, deficiencias de los sistemas sanitarios, condiciones laborales, factores bélicos, valores transmitidos por los sistemas educativos, etc. Factores que podríamos ampliar y diseccionar.

2. Factores intermedios o próximos o cercanos. Estos factores vendrían, en gran parte, emanados como productos más o menos específicos a medio y largo plazo, de los factores del primer nivel. Así, podríamos enunciar los siguientes: desigualdades socioeconómicas en una determinada comunidad, crisis socio-económicas, zona depauperada de una ciudad, paro o jubilación de los padres, dificil acceso a la cultura y a la educación, desintegración familar, bajo nivel de autonomía y autoritarismo, problemas de convivencia familar, coacciones y malos ejemplos de los padres, rigidez mental en la familia y en la escuela, presión grupal, degradación del medio ambiente cercano, físico y humano, deshumanización de las realidades humanas, desintegración de los valores culturales, carencia de infraestructuras cercanas de tipo cultural, educativo o sanitario, experiencias traumáticas infantiles, trastornos previos de la personalidad, características personales previas, discriminación racial, racismo o discriminación regional, falta de oportunidades sociales, laborales o intelectuales, ausencia de seguridad en el trabajo, pobreza, falta de consideración social, etc.

Junto a estos factores próximos comunes o generales estarian más específicamente, o como factores próximos más específicos, la pertenencia a una familia con drogodependientes, oferta y disponibilidad de drogas, biogénesis o antecedentes de drogadicción en los padres (exposición a la droga durante la gestación, falta de una adecuada información en relación con las drogas, influencias de los "mass media", publicidad, propaganda, actitudes sociales ante la salud, las drogas y los consumidores de drogas, etc.

Finalmente y como «subproducto» de los anteriores factores tendríamos los:

3. Factores inmediatos, que podríamos llamar individuales, también «exteriores» o "superficiales», que, en realidad, en sí mismos, son más síntomas, indicadores y efectos que causas, pero que en un diagnóstico clínico o psicológico se presentan como factores determinantes y exclusivos de la drogadicción. 


\section{1}

3.1 Factores inmediatos comunes: Se trata de factores psicológicos como baja inteligencia, neuroticismo, desequilibrios psicoafectivos, inestabilidad emocional, inseguridad, falta de atención, fracaso escolar, sentimientos de culpabilidad, baja autoestima, falta de internalización de las normas sociales, falta de preparación para la toma de decisiones razonables, intolerancia a la frustración, carencias afectivas, ansiedad, depresión, inadaptación social, agresividad, etc.

Hasta aquí, los factores considerados en tres niveles interrelacionados conexionados; entendidos en una cierta sucesión, pero que si bien no dudamos que pueden conducir o contribuir al consumo abusivo de drogas, porque en la historia vital de los toxicómanos así aparecen, también somos conscientes de que pueden conducir a otro tipo de manifestaciones o salidas, mas o menos disfuncionales como una enfermedad psíquica grave, una conducta delictiva o ¿por qué no? una postura de crítica dura y de denuncia política y social de su propia situación y de la cumunidad en la que vive, de aquí que debamos avanzar en la búsqueda de factores más específicos y cercanos a la conducta concreta de la toxicomanía. Creo que puede ser útil heurísticamente denominar a los factores inmediatos referidos, factores inmediatos comunes o generales y tratar de discernir unos factores inmediatos específicos o más especificos o directamente relacionados con la toxicomanía.

Ya he indicado anteriormente que he hecho aquí una aplicación o inferencia del modelo explicativo causal referente a la delincuencia juvenil, aplicándolo también a la toxicomanía, y la verdad hay algunas razones para hacerlo así, ya que, según algunas investigaciones, observaciones y experiencias (Garrido Genovés, 1987), parece bastante claro que una parte importante de los que, antes de la aparición extendida de las drogas, eran simplemente delincuentes juveniles, hoy día, con similares características y genesis causal, además se drogan. Los jóvenes delincuentes de hoy día, en principio, no serían ni mejores ni peores que los de entonces: la droga y sus consecuencias haría sus actuales conductas más criminógenas y peligrosas y, por otra parte, con mayores y nuevas dificultades de reinserción social. Cuando en 1975 yo dirigiera el Reformatorio de Delincuentes Juveniles Difíciles de España, sito en Salamanca, aparte de un caso de alcoholismo, no teníamos más drogadictos. Hoy la toxicomanía es el mayor problema de los centros de tratamiento de jóvenes delincuentes. Da la impresión de que la drogadicción pudiera suplir o ser sucedáneo para los delincuentes juveniles de la mera conducta delictiva, «continuación de su conducta antisocial previa" (Valbuena Briones, 1993). También pudiera decirse que la drogadicción se añade o viene después de la conducta delictiva o, incluso, que la toxicomanía en cierta medida lleva a conductas delictivas, sobre todo por la necesidad de conseguir cada vez mayores dosis de drogas. No obstante, parece conveniente, tanto desde el punto de vista conceptual como desde la perspectiva de la intervención, separar la toxicomanía de la delincuencia, ya que estamos ante fenómenos diferentes con características propias (Valbuena Briones, 1993).

\subsection{Factores inmediatos específicos}

Puede pensarse que al lado de los factores etiológicos indicados sería necesaria la existencia en el sujeto o en el entorno social inmediato del drogadicto algo más específico que lo llevara al consumo concreto de drogas. Se habla de la existencia de una «actitud personal que induce al consumo o al abuso de estos productos» (Vega Fuente, 1985). Pero yo creo que, siguiendo la lógica intẹrna de esta clasificación, podemos indicar unos factores inmediatos específicos que expliquen la determinación concreta de los sujetos hacia las drogas y no hacia otras salidas. "La curiosidad por conocer los efectos y sensaciones subjetivas que producen las drogas", el deseo de adquirir rápidamente estados de relajación y sopor o búsqueda de placer o bienestar por medios farmacológicos, deseo de escapar y huir de los conflictos y problemas, fácil disponibilidad para adquirir drogas, actitudes positivas hacia las drogas y sus consumidores, información incorrecta sobre las drogas y sus riesgos, consumo habitual de alcohol, analgésicos o estimulantes en la familia, tener un hermano mayor drogadicto en la familia, cercanía a lugares de producción de opio u otras drogas, 
tener amigos que se drogan o ser miembro de una pandilla en la que se toman drogas, búsqueda de nuevas experiencias excitantes, entre otras motivaciones.

Todos los factores, condicionamientos y motivaciones considerados en los tres niveles hay que verlos integrados en un proceso dinámico, interrelacional y sistémico, en espiral, que nos pone en evidencia la complejidad del fenómeno de la drogadicción, las implicaciones socioeconómicas y socio-políticas, ambientales y humanas, en las que se hace patente las responsabilidades compartidas de todo el cuerpo social y nos hace ver la necesidad de la participación comunitaria en la solución del problema.

De todos modos, he presentado un modelo que precisaría de mayor precisión en su descripción y sobre todo una adecuada contrastación empírica en base a modelos de análisis e investigación coherentes con el propio modelo y realidad sistémica del fenómeno de la toxicomania. Los modelos analíticos de mera yuxtaposición de datos no son suficientes y posiblemente distorsionan más que informan sobre la realidad interrelacional y global del problema.

\section{«EPI-LOGOS»}

Para terminar, quiero volver a algunas ideas mencionadas al inicio de este

Entre los factores implicados en el fenómeno de la drogadicción, hemos hecho referencia al deterioro y degradación del medio humano, del medio «ambiente» humano, haciendo un paralelismo entre el medio ambiente físico o geográfico y la realidad humana, el medio humano, siguiendo la perspectiva del citado "proyecto Homo». Viendo en efecto, que «nuestra condición humana está también sometida a una explotación abusiva e irracional», que están sucediendo hechos y actuaciones que están degradando el medio humano y en los que la «construcción del hombre» está siendo cercenada directa $e$ indirectamente por esos hechos e intervenciones. Todo ello, en el convencimiento de que debe haber coherencia entre el medio ambiente físico y el medio «ambiente» humano, de la misma forma, p.ej., que debe haber relación entre el medio ambiente físico y la educación para la salud.

Tenemos hoy día en Occidente demasiadas ideologías, realidades, hechos, acciones y «empresas» contaminantes del medio humano, desde guerras cruentas, corrupciones económicas y políticas, marginaciones, racismos, torturas, etc., realidades todas que están deshumanizando el hecho humano. No nos debe extrañar que algunos de nuestros conciudadanos quieran huir y evadirse de este medio y se sientan asfixiados por la excesiva contaminación de la condición humana actual. También el medio humano puede agotarse y hacerse inhabitable, haciéndonos desaparecer como auténticos hombres. Si progresara en exclusiva nuestra preocupación por la ecología física, pudiera darse la paradoja, difícil de imaginar, de que llegáramos a subsistir como entes biológicos en un medio humano totalmente degradado.

El medio «ambiente» humano tiene que ver con el respeto a los derechos humanos, con la solidaridad, la hospitalidad, el respeto a la diferencia, con la fraternidad y filantropía, con la búsqueda de la justicia para todos, con la defensa del diálogo y la paz, entre otras muchas cosas más. De la cantidad y calidad de implementación en las relaciones de los hombres de todos estos aspectos depende la cantidad y calidad del medio humano.

Esperemos que la degradación del medio humano sirva cada vez menos como factor determinante de la drogadicción como huida. 


\section{Referencias}

GarRIDo Genovés, V. (1987). Delincuencia juvenil, orígenes, prevención y tratamiento. Madrid: Alhambra.

González, G. y Pérez de VIllar, G. (1993). Prevención de drogodependencia en la escuela. Madrid: Pablo Montesino, 11.

JiménEz BURILLO, F. y ARAGONES, (1986). Introducción a la psicología ambiental. Madrid: Alianza Editorial.

La dependencia de las drogas. Madrid: Dirección General de Salud Pública, (1981), 17.

Proyecto Homo, (1992). Madrid: Fundación Infancia y Aprendizaje.

OrTEGa EstebAN, J. (1978). Delincuencia, reformatorio y educación liberadora. Madrid: Zero-zyx.

REPETTO y Cols. (1985). Toxicología de la drogadicción. Madrid: Díaz de Santos, 95.

VALBUENA BrIONES, A. (1993). Toxicomanías y Alcoholismo. Barcelona: Masson-Salvat, $2^{\text {a }}$ ed., 49-51.

VEGA FUENTE, A. (1985). Las drogas ¿Un problema educativo?. Madrid: Cincel, 52.

\section{La drogadicción como huida. Condicionamientos sociales de las toxicomanías \\ José Ortega \\ CL\&E, 1995, 27, pp. 97-103}

Resumen: En este artículo se presenta una propuesta ecológica, sistémica y dinámica de comprensión de los condicionamientos sociales de las toxicomanías, estableciendo un paralelismo entre el medio ambiente físico y el medio ambiente humano. Se sigue dando importancia al estudio crítico de los factores influyentes en el abuso de las drogas para la prevención, la intervención y asunción de responsabilidades por parte del colectivo social.

Datos sobre el autor: José Ortega Esteban es Catedrático de Pedagogía Social en la Universidad de Salamanca y Decano de la Facultad de Ciencias Sociales de la misma Universidad.

Dirección: Facultad de Ciencias Sociales. Campus Miguel de Unamuno. 37007 Salamanca.

(C) PERMISOS PARA CITAR O REPRODUCIR EN OTRAS FUENTES: Se pueden citar libremente hasta 500 palabras. Para reproducir una porción de texto mayor, figuras o ilustraciones, se deberá pedir permiso por escrito a la revista, especificando el uso al que se destina el texto. En todos los casos, se deberá citar el copyright de $C L \& E$. En el caso de artículos o textos que hayan sido a su vez reproducidos en $C L \& E$ los interesados deberán dirigirse tanto a los detentadores del copyright original como a $C L \& E$, en el caso de que se quiera hacer uso de la traducción. FOTOCOPIAS: Para todo lo relacionado con el uso mediante fotocopia del material de esta revista, deberán dirigirse a: CEDRO, C/ José Marañón, 10, 3. ${ }^{\circ}$ Izda. Tel. 594 15 75. Fax 4453567 